in pathological conditions a true disproportionate depression of the colour field is common. For this reason it is desirable, as Roenne ${ }^{(2)}$ points out, in estimating the relationship of isopters for colour to those for white, to use objects whose isopters normally lie together (e.g., 10/300 red and 10/2000 white: Roenne $\left.{ }^{(2)}\right)$. The statement that contraction of the colour field exceeds or precedes contraction of the field for white must, therefore, be carefully scrutinized in relation to the sizes of the objects employed. If the colour test used gives an isopter lying normally considerably above that corresponding to the white test an apparent undue loss for colour may be discovered quite apart from anv special impairment of colour perception.

The fourth essential is :

IV. In all perimetric work the size of each test object and its distance from the eye should be carefully selected with a view to the requirements of the individual case and should be recorded.

\title{
LITERATURE
}

1. *Roenne.- "Ueber das Gesichtsfeld beim Glaukom." Klin. Monatsbl. f. Augenheilk., Vol. I, p. 12, 1909.

2. "Idem.- " Gesichtsfeldsstudien über das Verhältnis zwischen der peripheren Sehschärfe und dem Farbensinn speziell die Bedeutung derselben für die Prognose der Sehnervenatrophie." Ibid., Vol. I., p. 154, Feb., 1911.

3. "Idem. - "Zur Theorie und Technik der Bjerrumschen Gesichtsfelduntersuchung." Arch. f. Augenheilk., Vol, LXXVIII, Pt. iv., 1915.

4. *Traquair. - "The Quantitative Method in Perimetry with Notes on Perimetric Apparatus." Ophthal. Rev., p. 65, 1914.

\section{BUEDINER'S MODIFICATION OF DIFFENBACH'S OPERATION FOR EARLY EPITHELIOMA OF THE LOWER LID}

\author{
BY \\ Major R. E. Wright, I.M.S., \\ SUPERINTENDENT, GOVERNMENT DPHIHALMIC HOSPITAL, MALRAS
}

AN epithelioma of the lower lid satisfactorily dealt with by Buediner's operation is perhaps sufficiently uncommon to merit a published note. Briefly it consists in removal of the lower lid and its conjunctiva by two incisions starting at the canthi and meeting on the cheek below. The triangular skin defect thus produced is made good by carrying a horizontal incision from the outer canthus for a distance somewhat greater than the length 
of the lid margin, and another from the termination of this downwards parallel to the other side of the triangle. The flap thus defined is dissected up, slid nasalwards, and anchored with its superior side in the position originally occupied by the free edge of the lower lid. Before anchoring it, however, the tarsus and conjunctiva are replaced by a composite flap from the back of the ear. This consists of semilunar pieces of skin and cartilage, still attached to each other, and having a common straight edge somewhat shorter than the edge of the cheek flap. The skin is approximately three-quarters of a circle, the cartilage one quarter. This flap is applied to the deep surface of the skin flap from the cheek, straight edge to straight edge, the surface epithelium of the ear skin towards the globe. It is held in this position by two or three double-armed sutures, which are passed from behind

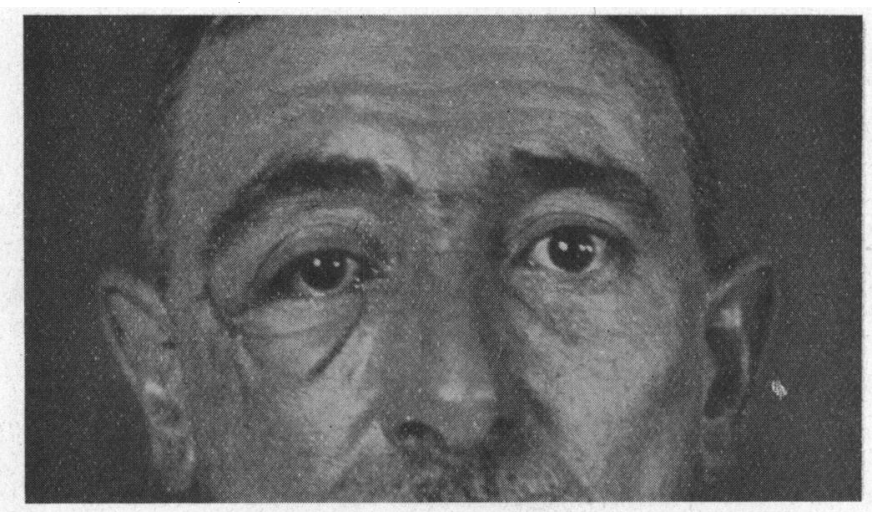

forward a short distance below the free edge, and tied externally on beads. The triangular, bare area on the cheek is filled in by a graft as soon as possible. Naturally, such a procedure can only be adopted in the case of a very limited malignant growth such as that described below:-

B.P., European, aged 50, noticed a small wart on the skin of the right lower lid near the lashes on September 20, 1920. On October 20,1920, there was a distinct yellowish hemispherical elevation two-and-a-half $\mathrm{mm}$. in diameter about the centre of the lid, and one $\mathrm{mm}$. below the lashes. The conjunctiva was not involved. On the summit there were a few bleeding papillae. The patient stated that he had scratched a tiny scab off it. A small wedge was removed from the growth which on examination proved to be epitheliomatous. The preauricular gland was normal on section. On November 6, 1920, .Buediner's operation was performed. Further, the horizontal incision was continued to the 
external ear and here a vertical incision was made an inch each side of the former one. This latter modification was made in order to gain access to the subcutaneous tissues and preauricular gland. These were freely dissected awav. This was perhaps the most tedious part of the operation, and, as might have been expected, was accompanied by considerable haemorrhage. The extensive undermining did not lead to any subsequent trouble. The angles of the cheek flap were held in position by two deep sutures tied over rubber tubing, and although at the time of operation there was no tension at the inner canthus, the inner angle of the flap commenced to drag outwards within a day or so. This might have been avoided if other supporting deep sutures had been placed internally. It appeared to be chiefly due to contraction in the triangular bare area, and so this was levelled by pressure and

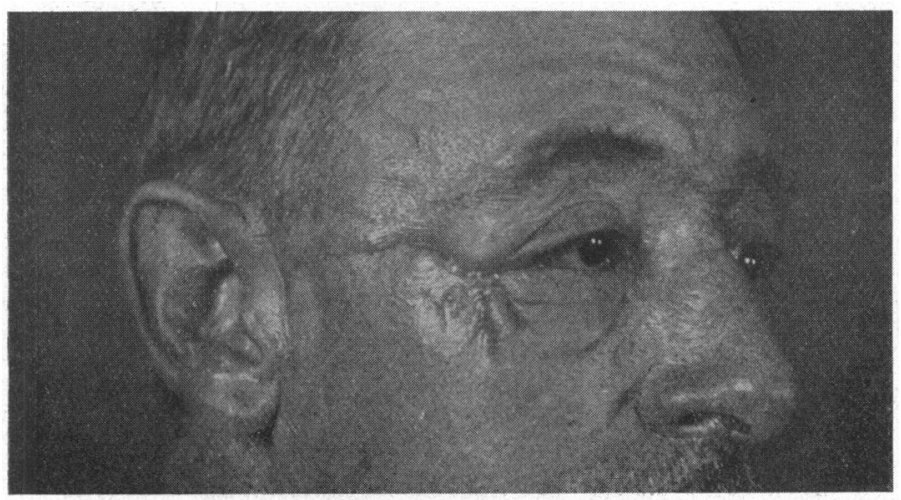

planted with Reverdin's grafts. On November 20, 1920, the skin flap was freed at its inner and outer sides and the inner angle accurately readjusted. An upward and inward drag was secured by deep sutures whilst the same object was aided by pressure over the granulating area. On November 24 this was planted with grafts and subsequent progress was uneventful. The triple flap contracted slightly, but sufficient redundant tissue had been taken to allow for this. The cosmetic result was somewhat impaired by the extent of the incision, but an efficient lower fornix was established allowing free movement and easy closure. There was considerable oedema of the outer angle of the upper lid which persisted for a long time. It would appear to be unnecessary to anchor the upper lid with a stitch, as good lubrication and careful bandaging suffice to prevent damage to the cornea.

The cicatricial contraction during the healing of the raw area is, doubtless, the weak point in the operation. Partial closure of 
the skin defect by deep sutures does not seem to be desirable. Flat pressure with early grafting is probably preferable. It might perhaps be better to utilize a large cheek flap with an upper border much longer than required, thus throwing the raw area further out, or to make a second cheek flap to fill in the raw area left by. the first. There does not appear to be any advantage in shaving down the ear cartilage to a thin lamella, but sufficient allowance must be made for the shrinkage of both skin and cartilage, and a very much bigger flap of skin should be supplied than, in the absence of experience, one would have thought necessary. There is no need to fear deformity of the ear if strict asepsis is observed. Very careful dressings are essential, to keep the cornea lubricated, to prepare the granulating area for grafts, to keep these in situ when planted, and to prevent large stitch erosions. Dilute yellow oxide ointment, vaseline, gauze netting, and wet picric acid dressings were employed for these various purposes. Seen three months after operation, the case presented the features shown in the photographs. The obvious defects as observed at this time were: irritation due to the outermost hairs of the upper lid, inaccurate apposition of the outer angle, slight oedema of the upper lid, and shrinkage of the ear flap with a slight entropion. These do not appear to detract from the practical efficiency of the result. The cornea is perfectly covered during closure of the lids.

\section{COUNCIL OF BRITISH OPHTHALMOLOGISTS}

\section{Interim Report on the Administration of Optical Benefits by Approved Societies}

In accordance with Section 37 of the National Insurance Act, 1911, an Approved Society in respect of which a surplus, certified by the Government Valuer to be disposable, is found on valuation, may submit to the Minister of Health a scheme for distributing out of such surplus any one or more additional benefits. Amongst these additional benefits is "the payment of the whole or any part of the cost of optical treatment and appliances" (Statutory Rules and Orders, 1921, No. 877).

In October, 1921, the Council of British Ophthalmologists were informed that certain Approved Societies were entering into negotiations with sight-testing opticians for the provision of optical benefit, i.e. examination of the eyes and provision of glasses.

The Council immediately wrote to the Ministry of Health on 